\title{
AOS VENCEDORES, O DIREITO A QUÊ?
}

O número 74 da Revista do Instituto de Estudos Brasileiros apresenta um importante dossiê em torno a um dos mais destacados intelectuais brasileiros no campo da teoria literária, Roberto Schwarz, autor de Ao vencedor as batatas (I977) e Um mestre na periferia do capitalismo (I990), entre tantas outras obras. A abrangência de seu pensamento dentro e além da crítica literária, com implicações no campo da sociologia, é debatida com propriedade ao longo de onze textos e uma atenta apresentação escrita por Maria Arminda do Nascimento Arruda, além de nota introdutória de Lidiane Soares Rodrigues, organizadora da seção Dossiê.

Na parte do fluxo contínuo da revista, este número apresenta uma análise da obra O cortiço (I890), de Aluísio Azevedo, na senda do drama burguês de Émile Zola, a partir da crítica de Antonio Candido. Em "Materialismo corticeiro", Lindberg S. Campos Filho repropõe e analisa a hipótese de Candido sobre a presença de elementos na literatura de Aluísio Azevedo que prenunciariam o surgimento de uma crítica cultural materialista no Brasil no início do século XX.

A indumentária e as vestes, que figuram nos álbuns litográficos de Jean-Baptiste Debret e que compõem Viagem pitoresca e histórica ao Brasil (I834-I839), são o tema do artigo "A obra de Jean-Baptiste Debret como fonte histórica para os estudos dos trajes usados no Brasil no início do século XIX”, de Marli Gomes de Araújo, João Paulo Pereira Marcicano e Maria Sílvia Barros de Held. Os autores delimitam a análise ao campo da moda, sugerindo que os trajes usados no Brasil à época seguem de perto os "estilos" europeus do período joanino.

No artigo "Recreação e vida ao ar livre em parques infantis de São Paulo na coleção de desenhos de Mário de Andrade”, de Ingrid Dittrich Wiggers e Carmen Lucia Soares, encontra-se uma interpretação atualizada do conjunto de mais de 2 mil desenhos infantis colecionados por Mário de Andrade à época em que foi diretor do Departamento de Cultura da cidade de São Paulo e guardados hoje no Instituto de Estudos Brasileiros. As autoras revisitaram essa coleção, tendo por base o inventário feito por Telê Ancona Lopez, a partir de I984, focalizando os jogos e brincadeiras ilustrados pelas próprias crianças, assim como a relação desses jogos com o espaço urbano circunstante à época.

No espaço Resenhas, Silvio Luiz de Almeida analisa o novo livro de Lilia Moritz Schwarcz, Sobre o autoritarismo brasileiro, que se propõe a investigar as origens do autoritarismo brasileiro. Em "A história e a disputa dos sentidos: sobre o autoritarismo no país", o autor afirma que a disputa pelos "sentidos de óbvio humano" e pelos "processos de constituição de vida social" é política e, como 
tal, constitui as bases da formação ideológica quanto às noções de liberdade e de nação, entre outras. As bases do autoritarismo presente estariam esgarçadas e entranhadas na constituição da sociedade brasileira, segundo a autora, e assentindo o resenhista, sendo fundamental analisar o passado para compreender o presente, por exemplo, quando nos deparamos com a persistência desse autoritarismo nas redes sociais atuais da internet.

Na seção Documentação, Eduardo Soares Neves Silva anuncia a existência de uma correspondência entre Roberto Schwarz e Theodor Adorno, tendo-a como basilar para a compreensão da contribuição teórica do último sobre o primeiro. Em "Schwarz-Adorno: Unbekannt verzogen - endereço desconhecido. Apresentação de uma correspondência", Silva especula sobre a formação das principais teses de Schwarz, à época em que se dá o dialogue in absentia, abrindo a possibilidade, a título de hipótese, de a obra schwarziana ser lida à luz do pensamento adorniano do início da década de I960. Por fim, Viviane Panelli Sarraf e Karoliny Aparecida de Lima Borges, em "O pensamento intelectual e sua preservação: uma análise a partir do Fundo Waldisa Rússio" apresentam-nos brevemente o Fundo Waldisa Rússio Camargo Guarnieri, doado ao IEB em I992 (ABC DO IEB, I997, p. I42). Rússio foi uma museóloga importante no decênio de I970, e seu acervo pessoal, embora ainda não organizado ou "fora da lógica de uma produção teórica", é de fundamental importância, segundo as pesquisadoras, para a questão da museologia e da preservação do patrimônio no país, desde que os vários e diversos níveis de informações coletados possam ser considerados à luz de seu contexto.

Fernando Paixão ${ }^{\mathrm{I}}$, Luiz Armando Bagolin² ${ }^{2}$ Monica Duarte Dantas 3

Editores

\section{SOBRE OS AUTORES}

FERNANDO PAIXÃO é docente do Instituto de

Estudos Brasileiros da Universidade de São Paulo (IEB/USP).

E-mail: fernando.paixao@usp.br

https://orcid.org/o000-000I-5I57-I506

LUIZ ARMANDO BAGOLIN é docente do IEB/USP.

E-mail: lbagolin@usp.br

https://orcid.org/oooo-oooI-65I3-2846

MONICA DUARTE DANTAS é docente do IEB/USP.

E-mail: mddantas@usp.br

https://orcid.org/o000-0002-I03I-9408

I Universidade de São Paulo (USP, São Paulo, SP, Brasil).

2 Universidade de São Paulo (USP, São Paulo, SP, Brasil).

3 Universidade de São Paulo (USP, São Paulo, SP, Brasil). 
PAIXÃO, Fernando; BAGOLIN, Luiz Armando; DANTAS, Monica Duarte. Aos vencedores, o direito a quê?. Revista do Instituto de Estudos Brasileiros, Brasil, n. 74, p. I3-I5, dez. 2019.

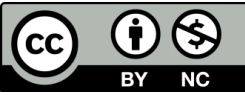

DOI: http://dx.doi.org/Io.II606/issn.23I6-90IX.voi74pI3-I5

Recebido em I2 de novembro de 2019

Aprovado em I9 de novembro de 20 I9

\section{REFERÊNCIA}

ABC DO IEB: Guia Geral do Acervo. Coordenação geral Marta Rossetti Batista. São Paulo: Edusp, I997. 